\title{
Music And VAgue EXIsTenCE
}

\author{
David Friedell
}

\begin{abstract}
I explain a tension between musical creationism (the view that musical works are abstract artifacts) and the view that there is no vague existence. I then suggest ways to reconcile these views. My central conclusion is that, although some versions of musical creationism imply vague existence, others do not. I discuss versions of musical creationism held by Jerrold Levinson, Simon Evnine, and Kit Fine. I also present two new versions. I close by considering whether the tension is merely an instance of a general problem raised by artifacts, both abstract and concrete. I argue that on at least one defensible account of music the tension is especially problematic for abstracta. I focus on musical works, but much of the paper straightforwardly applies to other kinds of abstract artifacts.
\end{abstract}

\section{Introduction}

Abstract creationism about music-or musical creationism for short-is the view that musical works are abstract artifacts. ${ }^{1}$ Abstract artifacts, roughly, are objects with no spatial location that people create. Other potential abstract artifacts include fictional characters, words, corporations, novels, poems, treaties, contracts, cookbooks, and reggae bands. ${ }^{2}$

This paper is about musical creationism and vague existence. Many theorists think there is no vague existence (e.g., Lewis 1986, Markosian 1998, and Sider 2001). I take no stand here. I instead focus on whether musical creationism implies vague existence. It is compelling to think, as Daniel Z. Korman (2014) suggests, that realism about abstract artifacts (musical or otherwise) implies vague existence. The basic idea-to be explained in more detail below-is that if there are abstract artifacts, then it's indeterminate when people create them and thus indeterminate when they first exist. And, the idea goes, the only way to account for the

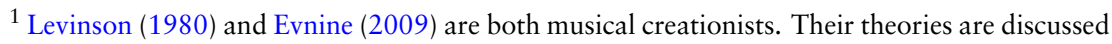
below.

${ }^{2}$ See Kripke 2013, Salmon 1998, von Solodkoff 2014, and Thomasson 1999 for examples of abstract creationists about fictional characters. See Kaplan 1990 for a version of abstract creationism about words and Cole 2004 for one about corporations.
} 
indeterminacy in this case is to posit vague existence. I agree with Korman that there is a real tension: a tension between musical creationism and the view that there is no vague existence. Pace Korman, though, I think these two views can be reconciled.

The paper proceeds as follows. I begin by characterizing vague existence (section 2). I then explain the tension between musical creationism and the view that there is no vague existence (section 3). Next, I suggest ways to reconcile these views (section 4 and section 5). In doing so I show that, although some versions of musical creationism imply vague existence, others do not. I close by considering whether the tension involving music and vague existence is merely an instance of a general problem raised by artifacts, both abstract and concrete (section 6). I argue that on at least one defensible account of music the tension is especially problematic for abstract artifacts. The paper focuses on musical works, but much of it straightforwardly applies to other kinds of abstract artifacts.

Before diving in, it's worth emphasizing the importance of vague existence. David Lewis (1986, 212-213) and Ted Sider (2001) reject vague existence to argue for unrestricted composition: the view that any two or more objects compose an object. Sider's Vagueness Argument for fourdimensionalism also rejects vague existence (Sider 2001, 120-149). So does Ned Markosian's (1998) argument for brutal composition: the view that it is a brute fact when composition occurs. The acceptance of vague existence would accordingly cast doubt on unrestricted composition, fourdimensionalism, and brutal composition. The acceptance of vague existence might also vindicate versions of neo-Aristotelianism, such as Simon Evnine's (2016). ${ }^{3}$ It's intrinsically interesting whether there is vague existence, and thus it's interesting whether musical creationism implies vague existence. But much more is at stake.

\section{Vague Existence}

Following Peter van Inwagen (1990) and Katherine Hawley (2001, 125$140)$, I characterize cases of vague existence as conflicting with the following principle: if it's indeterminate whether there exists something that has a certain property, then there exists something that indeterminately has that property. This principle may be formally represented as follows:

$$
\nabla \exists \mathrm{xFx} \rightarrow \exists \mathrm{x} \nabla \mathrm{Fx}^{4}
$$

Typically, when it's indeterminate whether there exists something that has a certain property, something indeterminately has that property. It's indeterminate whether there is a big city in South Dakota, and something (Sioux Falls) is indeterminately a big city in South Dakota. It's indeterminate

\footnotetext{
${ }^{3}$ Evnine's neo-Aristotelianism, as discussed below, implies vague existence.

4 ' $\nabla$ ' is an indeterminacy operator. The only sort of indeterminacy considered in this paper is due to vagueness.
} 
whether there is a ripe tomato in my kitchen, and a particular tomato is indeterminately a ripe tomato in my kitchen. To borrow an example from van Inwagen (1990, 271): if Socrates is the wisest person but is still only borderline-wise, then it's indeterminate whether there is someone who is wise, and someone (Socrates) is indeterminately wise. These cases do not involve vague existence. The source of indeterminacy in each case is a vague term (or concept) other than 'exists': 'big city,' 'ripe,' and 'wise,' respectively. ${ }^{5}$

In cases of vague existence, it is indeterminate whether there exists something that has a certain property, but nothing indeterminately has that property. Van Inwagen (1990) would say the unhealthy hamster is such a case. ${ }^{6}$ Imagine a hamster is dying on a mat. At some time it's indeterminate whether the hamster is still alive; it's indeterminate whether there exists a hamster on the mat. Many of us would say that something on the mat is indeterminately a hamster and indeterminately a corpse. Van Inwagen, however, doesn't believe in corpses. He believes instead in simples (i.e., things with no proper parts) arranged corpse-wise. He thinks simples and living organisms are the only concreta. For him, then, it's indeterminate whether there is anything (other than simples) on the mat. It's indeterminate whether there is a hamster on the mat, but nothing is indeterminately a hamster on the mat. Hence, van Inwagen would think this case is a counterexample to ' $\nabla \exists \mathrm{xFx} \rightarrow \exists \mathrm{x} \nabla \mathrm{Fx}$ ' and a case of vague existence.

I agree with Hawley $(2001,129)$ that the distinctive feature of cases of vague existence is that they conflict with this principle. Accordingly, I take the view that there is no vague existence to involve a commitment to $' \nabla \exists \mathrm{xFx} \rightarrow \exists \mathrm{x} \nabla \mathrm{Fx} .{ }^{7}$

\section{The Tension Involving Musical Creationism}

I will now explain the tension between musical creationism and the view that there is no vague existence. My explanation is similar to, but more direct than Korman's (2014) discussion. ${ }^{8}$ I begin with Jerrold Levinson's (1980) seminal version of musical creationism.

It's natural to think musical works in the Western classical tradition are abstract structures (or sequences) of sound types (e.g., the sound a violin

\footnotetext{
${ }^{5}$ Plausibly, in genuine cases of vague existence the source of indeterminacy is 'exists.' Korman $(2015,177-181)$, however, argues that in some cases of vague existence composition is the source of indeterminacy.

${ }^{6}$ I borrow this case from Hawley 2001, 128.

${ }^{7}$ Carmichael (2011) and Noonan (2010) informally prove that supervaluationists who think 'exists' is precise are committed to ' $\nabla \exists \mathrm{xFx} \rightarrow \exists \mathrm{x} \nabla \mathrm{Fx}$.

${ }^{8}$ Korman (2014) argues that Sider's vagueness argument for unrestricted composition-an argument that rejects vague existence-and an analogous argument for anti-realism about abstract artifacts stand or fall together. My presentation of the tension eschews Sider's argument and focuses on the view that there is no vague existence.
} 
makes when it plays a middle C). ${ }^{9}$ Levinson rejects this view. He thinks composers create musical works; for instance, he thinks Beethoven created the Ninth Symphony. ${ }^{10}$ But composers do not create sound structures, since sound structures are eternal (or at least exist before composers engage with them). Levinson thinks a composer creates a work by indicating a sound structure. This generates a new object, an indicated sound structure. The preexistent sound structure still exists, but the indicated sound structurewhich is the musical work-is distinct. ${ }^{11}$ It is mysterious exactly what an indicated sound structure is. I discuss related proposals below. For now, let's set aside such details and suppose that Levinson's theory, as just sketched, is correct.

A problem arises for ' $\nabla \exists \mathrm{xFx} \rightarrow \exists \mathrm{x} \nabla \mathrm{Fx}$.' When Beethoven indicated a sound structure that corresponds to the Ninth Symphony, he created the symphony. When did this happen? The question is difficult for two reasons. First, it's difficult to identify even vaguely when indication occurs, and thus, when a musical work begins. Is it when the composer writes the last note or makes some physical record of it? Is it when the composer mentally records the last note? Is it when the composer deems the work complete by thinking, "Now it's finished," or something similar? There's no easy answer. This difficulty is one of ignorance. We are ignorant (or at least I am) about what kind of event generates musical works. ${ }^{12}$

The second difficulty, more important for our purposes, is one of vagueness. Following Korman $(2014,67)$ we may note that, regardless of which event generates the Ninth Symphony, it's indeterminate when that event happens. ${ }^{13}$ Suppose Beethoven writes the final note on paper. There's no time $t$ such that at $t$, but not a nanosecond before, the note has been written. If an ultra-advanced video camera were to film the process at a billion frames per second, and we were to watch the tape frame by frame, no frame would strike us as the first to represent the note as having being written. Similarly, if Beethoven thereupon thinks, "Now it's finished,"

\footnotetext{
${ }^{9}$ I focus here, as Levinson does, on works in the Western classical tradition. It's implausible that works in genres that emphasize improvisation, such as jazz, are sound structures or even associated with individual sound structures. I think the central issues concerning vague existence still arise for jazz works, but I will not argue for that here.

${ }^{10}$ Musical Platonists (e.g., [Kivy 1983] and [Dodd 2007]) think musical works are discovered instead of created.

${ }^{11}$ Levinson's view is more nuanced than presented here. Musical works for him are not merely indicated sound structures, but are indicated sound/performance means structures. The basic idea is that it's built into the work not only how it sounds, but also how it is performed, including what instruments are used. I set aside this complication (as Levinson himself often does).

${ }^{12}$ I am open to the idea that a musical work comes into existence sometime in the middle or even close to the beginning of the composition process. See, for example, Trogdon and Livingston (2014) for discussion of when an artwork is complete.

${ }^{13}$ Korman similarly argues that it's indeterminate when Richard Dawkins created the word 'meme.'
} 
there's no nanosecond when that mental event first counts as having happened. Analogous facts obtain about any event that plausibly generates the symphony.

This second difficulty reveals that at some time $t$ it's indeterminate whether Beethoven has indicated the relevant sound structure. It's indeterminate at $t$ whether the symphony exists. Since it's Beethoven's only choral symphony, at $t$ it's indeterminate whether there exists a Beethovenian choral symphony. ' $\nabla \exists \mathrm{xFx} \rightarrow \exists \mathrm{x} \nabla \mathrm{Fx}$ ' implies that at $t$ something is indeterminately a Beethovenian choral symphony. What thing is it? It isn't the sound structure itself, since it (on Levinson's theory) is distinct from the symphony. It seems at first glance that nothing is indeterminately a Beethovenian choral symphony. It seems we have a counterexample to ' $\nabla \exists \mathrm{xFx} \rightarrow \exists \mathrm{x} \nabla \mathrm{Fx}$ ' and a case of vague existence. ${ }^{14}$

One might object that before the Ninth Symphony exists a 'protosymphony' exists. When it's indeterminate whether there exists a Beethovenian choral symphony, something is indeterminately a Beethovenian choral symphony and indeterminately a proto-symphony. Even if this is right, there must be a first abstract object Beethoven creates while composing the symphony. Whatever it is, it's problematically indeterminate when it first exists.

And so we have a problem. It's hard to reconcile musical creationism with the view that there is no vague existence. Next, I'll discuss potential reconciliations.

\section{Perdurantism}

Some perdurantist and neo-Aristoelian theories of music offer ways to reconcile musical creationism with a denial of vague existence. Let us start with perdurantism. Perdurantists are four dimensionalists who think ordinary objects persist by perduring — by having temporal parts at every moment they exist. It makes sense for perdurantists to think sound structures, despite being abstract, also perdure. Here's a perdurantist account of music: a musical work is a mereological sum of a sound structure's instantaneous temporal parts (i.e., time-slices) that exist after the composer indicates the sound structure. ${ }^{15}$ Perdurantists have similar views about concreta. They commonly think a clay statue is composed of a lump of

\footnotetext{
${ }^{14}$ I presuppose that the quantifier ranges over only (actual) presently existing objects. This precludes the defense of ' $\nabla \exists \mathrm{xFx} \rightarrow \exists \mathrm{x} \nabla \mathrm{Fx}$ ' that since there is a future Beethovenian choral symphony it isn't indeterminate at $t$ whether there is a Beethovenian choral symphony. One who insists the quantifier ranges over future objects should consider a world that suddenly ends while a composer has indeterminately created a symphony. Baker (2007, 130-132), relatedly, invokes eternalism in order to deny vague existence.

${ }^{15}$ It's natural to wonder what exactly a time-slice of a sound structure is. Sound structuressequences of sound types-are typically thought to be kinds of sets. The perdurantist will likely take slices of sound structures to be abstract slices of sets and not sets themselves. Granted, this ontology is mysterious, but that's at least partially because abstracta generally
} 
clay's time-slices that exist after a sculptor appropriately shapes the clay (until the clay is no longer appropriately shaped). ${ }^{16}$

This perdurantist proposal does not imply vague existence. Here's why. At some times it's indeterminate whether Beethoven has indicated the Ninth Symphony's sound structure. Suppose these times are $t_{1}-t_{100}$. Call the sound structure ' $s$ ' and the last time $s$ exists ' $t_{\mathrm{n}}$.' There is a mereological sum composed of $s$ 's time-slices from $t_{1}-t_{\mathrm{n}}$. Another sum is composed of $s$ 's slices from $t_{2}-t_{\mathrm{n}}$. And so forth. Whenever it's indeterminate whether there exists a Beethovenian choral symphony, one of these sums exists and is indeterminately a Beethovenian choral symphony. There's no vague existence, just vague symphony-ness. The sums have definite durations. It's indeterminate merely which one 'the Ninth Symphony' refers to. This story resembles Lewis's famous story about the outback:

The reason it's vague where the outback begins is not that there's this thing, the outback, with imprecise borders; rather there are many things, with different borders, and nobody has been fool enough to try to enforce a choice of one of them as the official referent of the word 'outback.' $(1986,212)$

The perdurantist proposal, though, raises concerns. One issue pertains to creation. Time-slices of $s$ (the Ninth Symphony's sound structure), according to the perdurantist, always come into existence-one at every instant, in fact. This plenitude of generation occurs automatically without Beethoven doing anything. Call the mereological sum of $s$ 's slices that just so happen to exist after Beethoven indicates $s$ 'SUM.' Presumably, SUM would have existed even if Beethoven had never been born. The perdurantist, however, identifies SUM with the symphony. Thus, although the symphony on the perdurantist proposal comes into existence at the time of indication, one might worry the perdurantist cannot make sense of Beethoven creating the symphony. ${ }^{17}$

In response, the perdurantist may claim that when Beethoven indicated $s$ he thereby indicated the symphony and SUM; analogously, the perdurantist thinks that when you touch a table you touch some of its temporal parts. Moreover, and this is the crucial point, the perdurantist may claim the symphony is essentially indicated. ${ }^{18}$ SUM, though indicated, is not essentially

are mysterious. See Sider 2001 for discussion of perdurantism. Caplan and Matheson (2006) defend a perdurantist theory of music, but on their view musical works are concrete.

${ }^{16}$ On the current proposal, a musical work, after being created, exists as long as its sound structure exists. Some might think musical works cease to exist when there is no record or memory of them. Such theorists may offer a variant: a musical work is composed of a sound structure's slices that exist after a composer indicates the sound structure until there is no record or memory of the appropriate kind. My remarks apply also to this variant.

${ }^{17}$ Korman $(2014,68)$ raises a similar concern regarding a different conception of words.

18 The perdurantist may also claim the symphony is essentially part of a sound structure that has been indicated. This claim is less elegant but works the same for present purposes. 
indicated. That the symphony and SUM have different essential properties might seem to entail they are distinct. But the perdurantist may argue they are identical. One strategy would be to invoke a counterpart-theoretic view of de re modality. Another strategy would be to claim the symphony and SUM are contingently identical. ${ }^{19}$ I won't endorse any strategy here. My point is, there is room for the perdurantist to claim (a) the symphony is identical to SUM, and (b) the symphony (but not SUM) is essentially indicated. From (b) the perdurantist may infer that had Beethoven not indicated $s$, the symphony wouldn't have existed, and thus, that Beethoven did in fact create it via indication.

Another concern with the perdurantist proposal pertains to simultaneity. Imagine we live in a mirror world: a world with "a symmetry in the mosaic of events with respect to some spatial axis" (Hawthorne 2007, 429). When Beethoven indicates $s$, so does his atom-for-atom duplicate, MirrorBeethoven. The two composers are far apart and unaware of each other. On the perdurantist proposal, the composers' symphonies are identical sums, composed of the same time-slices of $s$. They unknowingly co-create a symphony. This is odd. ${ }^{20}$

Things get stranger. Imagine another scenario: everything is as before, except a quantum miracle causes Beethoven to compose his symphony a nanosecond before Mirror-Beethoven composes his. On the current proposal, the composers create two distinct symphonies that sound exactly alike. The symphonies are distinct sums that share most but not quite all of the same slices of $s$; Mirror-Beethoven's symphony is a proper part of Beethoven's symphony. These results when taken together are especially odd. It's reasonable to think, as Levinson $(1980,10)$ does, that people far apart may create distinct musical works that sound exactly alike. It's also reasonable to accept the Platonist view that when people compose works that sound exactly alike, they merely discover the same work. It is odd, however, to accept that whether the composers create one or two symphonies depends on whether they indicate $s$ at exactly the same time. A nanosecond, one might think, shouldn't affect the number of symphonies. The issue is not unique to mirror worlds. It arises in any world where two composers, unaware of each other, simultaneously compose works that sound exactly alike. ${ }^{21}$

\footnotetext{
${ }^{19}$ See, for instance, Lewis 1971 for discussion of counterpart theory and Gibbard 1975 for a defense of contingent identity.

${ }^{20}$ Predelli $(2001,285)$ makes a similar point about an example raised by Currie $(1989,62)$. It's arguably misleading to say the composers co-create a symphony. For one thing, this phrasing evokes a sense of teamwork. Moreover, the perdurantist may claim the Ninth Symphony is essentially indicated by Beethoven and not essentially indicated by Mirror-Beethoven and that the mirror-symphony is essentially indicated by Mirror-Beethoven and not essentially indicated by Beethoven. This suggests that only Beethoven creates the Ninth Symphony and that only Mirror-Beethoven creates the mirror-symphony. It's unclear how helpful this approach is, however, since the symphonies still count as being identical.

${ }^{21}$ One might worry I've illegitimately invoked simultaneity, given Einstein's theory of special relativity. But special relativity doesn't resolve the problem. If we fix a frame of reference, the
} 
Perhaps we should not be so troubled by this simultaneity problem. After all, when discerning the metaphysics of musical works oddness is expected. Despite the issues raised here, the perdurantist view is worth further consideration. Some theorists might be particularly attracted to the view, given that it does not imply vague existence.

\section{Neo-Aristotelianism}

We now consider neo-Aristotelian proposals. On these proposals, musical works are constituted by, but distinct from, sound-structures. Similarly, neo-Aristotelians think clay statues are constituted by, but distinct from, their clay. Evnine (2009), inspired by Levinson, thinks when Beethoven indicated $s$ (the Ninth Symphony's sound structure) he made a symphony that was constituted by, but distinct from, $s$. His account implies vague existence. The reason why is that, for Evnine, constitution doesn't always occur. $S$ goes from constituting nothing to constituting something when Beethoven indicates it. Since it's indeterminate when indication occurs, it's indeterminate when $s$ first constitutes anything in a way that conflicts with ' $\nabla \exists \mathrm{xFx} \rightarrow \exists \mathrm{x} \nabla \mathrm{Fx}$.' At some time (around when $s$ first constitutes something) it's indeterminate whether there exists something constituted by $s$, but nothing is indeterminately constituted by $s$. Hence, Evnine's theory implies vague existence.

Other neo-Aristotelian theories, however, do not imply vague existence. Kit Fine suggests one. He thinks that for every property an object possesses, it automatically constitutes a 'qua object' (Fine 1982a). The-Eiffel-Towerqua-tall and The-Eiffel-Tower-qua-famous are distinct qua objects. Each is constituted by, yet distinct from, The Eiffel Tower. Fine suggests a musical work is a sound-structure-qua-having-been-indicated-by-composer-c. ${ }^{22}$

In order to see that the proposal does not imply vague existence, let us suppose there are no vague properties. There are merely vague predicates. 'Bald' is one. It's not that 'bald' refers to a single property with a vague extension. Rather, there are many precise properties regarding hair-for example, having fewer than 999,999 hairs; having fewer than 999,998

number of symphonies depends on whether Beethoven and Mirror-Beethoven simultaneously indicate $s$ (relative to that frame of reference). This is no less odd than the result considered above. Also, relative to some frames of reference-but not to others-Beethoven and MirrorBeethoven count as simultaneously indicating $s$. The odd upshot is that how many symphonies there are depends on one's frame of reference.

${ }^{22}$ Fine, inspired by Levinson, says something similar about stories: "Now when an author creates a story, he will bear a certain relation, what we may call 'indicating', to the abstract content of the story. We may then say the story is the abstract content under the description of having been indicated, in the way it was, by the author" (Fine 1982b, 131). Fine thereby suggests that stories are qua objects. He then claims a similar theory can be developed for musical works. Evnine (2009) reasonably suggests interpreting Levinson as thinking musical works are qua objects. In response, however, Levinson $(2013,56)$ denies works are qua objects. 
hairs; etc.- and it's indeterminate which one 'bald' refers to. Each is a precisification of 'bald.' This account explains why it is vague when most actions begin-dancing, singing, walking, etc. When one dances there's no exact nanosecond when dancing first occurs; dancing begins at different times on different precisfications of 'dancing.' As Lewis would say, nobody has been fool enough to enforce a choice of one precisification as the official referent of 'dancing.'

'Indicate' is also vague in this way. Suppose for simplicity it has 100 precisifications: indicate ${ }^{1}$, indicate ${ }^{2}$, etc. ${ }^{23}$ A composer who indeterminately indicates a sound structure indicates it on some, but not all precisifications. A composer who determinately indicates a structure does so on all such precisifications. Given that Beethoven has (by now) determinately indicated $s$, there are one hundred related qua objects: $s$-qua-having-been-indicated ${ }^{1}-$ by-Beethoven, $s$-qua-having-been-indicated ${ }^{2}$-by-Beethoven, etc. It's indeterminate which of these 's-qua-having-been-indicated-by-Beethoven' refers to, and hence (on Fine's view), to which of these 'the Ninth Symphony' refers.

Now, consider a time $t$ when it's indeterminate whether Beethoven has indicated $s$. At $t$ it's indeterminate whether there exists a Beethovenian choral symphony. ' $\nabla \exists \mathrm{xFx} \rightarrow \exists \mathrm{x} \nabla \mathrm{Fx}$ ' implies that something at $t$ is indeterminately such a symphony. Fine's proposal (along with the present account of vagueness) implies there is such a thing. Here's why. On some precisification of 'indicate'-say, indicate ${ }^{47}$-Beethoven has indicated $s$ at $t$. Thus, at $t$ there's a qua object: $s$-qua-having-been-indicated indicated ${ }^{47}$ by-Beethoven. This object is indeterminately the Ninth Symphony. It is thus, indeterminately, a Beethovenian choral symphony in accordance with ' $\nabla \exists \mathrm{xFx} \rightarrow \exists \mathrm{x} \nabla \mathrm{Fx}$. .' There's no vague existence, just vague symphony-ness. Moreover, no problem arises about when $s$ first constituted something. Fine thinks, pace Evnine, that $s$ has always constituted something.

Fine's proposal relies on a view we may call unrestricted constitution: the view that for each property an object has, it constitutes a unique qua object. This view implies there are many more objects than commonsense allows. There is, for instance, the Eiffel Tower-qua-taller-than-.01-meters, the Eiffel Tower-qua-taller-than-.02-meters, and so forth. Some will deem this too high of a cost. But others might find this abundant ontology palatable. After all, unrestricted composition - the popular view that any two or more objects compose an object-also implies an abundant ontology. There is, for instance, the sum of the Eiffel Tower and my nose. It's not obvious that Fine's ontology is any less plausible. Moreover, a common reason for accepting unrestricted composition is that it is consistent with there being no vague existence (Lewis 1986, 212-213). Perhaps it is reasonable to accept unrestricted constitution, given that it also is consistent with denying vague existence. At least, Fine's proposal is worth further consideration.

$\overline{{ }^{23} \text { I set aside higher-order vagueness. }}$ 


\section{How General Is The Problem?}

It is tempting to think the tension involving music and vague existence is merely an instance of a general problem raised by artifacts, including concrete ones. Imagine making a hammer-a concrete artifact-by connecting a hammer head to a handle. ${ }^{24}$ For the sake of simplicity, suppose it is the only hammer in the world. God has annihilated all others. Intuitively, there is no exact time when you create the hammer. At some time $t$, it's indeterminate whether there exists a hammer yet. ' $\nabla \exists \mathrm{xFx} \rightarrow \exists \mathrm{x} \nabla \mathrm{Fx}$ ' implies that something at $t$ is indeterminately a hammer. It's not obvious there is such a thing. In this way the creation of the hammer (and other concrete artifacts) poses a problem for the view that there is no vague existence. This problem is clearly similar to the one musical creationism poses. ${ }^{25}$

Moreover, the three extensions of Levinson's theory considered aboveperdurantism, Evnine's theory, and Fine's theory-all handle concrete artifacts in much the same way they handle music. Perdurantists may say the hammer is a four-dimensional worm composed of time-slices of the head and the handle that exist whenever the two are arranged hammerwise. More precisely, there are many overlapping worms of this sort, each corresponding to a different precisification of 'arranged hammer-wise.' The worms have definite durations; it's indeterminate merely which one is a hammer. Likewise, Fine could take the hammer to be a qua object: thehead-and-the-handle-qua-arranged-hammer-wise. More precisely, there are many related qua objects, each corresponding to a different precisification of 'arranged hammer-wise.' The qua objects have definite durations; it's indeterminate merely which one is a hammer. On the perdurantist and Finean proposals, then, there is no vague existence, just vague hammer-ness. ${ }^{26}$

This brings us to Evnine's theory. ${ }^{27}$ As we have seen, he thinks a symphony is constituted by its sound structure. He would say the hammer is constituted by its head and handle. His account of the hammer-like his account of symphonies-implies vague existence. For, at some moment during the creation of the hammer it's indeterminate whether there exists something that is constituted by the handle and the head, but nothing is indeterminately constituted by them. This result conflicts with ' $\nabla \exists \mathrm{xFx} \rightarrow$ $\exists \mathrm{x} \nabla \mathrm{Fx}$ ' and involves vague existence.

For both symphonies and hammers, then, perdurantism and Fine's view do not imply vague existence. In both cases Evnine's view does. This might make it seem even more likely that musical works and other abstracta pose

\footnotetext{
${ }^{24}$ I borrow this case from Korman 2014, 66.

${ }^{25}$ The problem pertains to the beginnings of concreta and also their endings-for example, when the hammer is destroyed.

${ }^{26}$ Although I've supposed the hammer's parts do not change, perdurantists and Fine can account for concrete artifacts with changing parts, such as a car that gets new tires. Fine (1999) invokes the notion of a variable embodiment for this purpose.

${ }^{27}$ See Evnine 2016 for his unified neo-Aristotelian theory of abstract and concrete artifacts.
} 
no special problem for the view that that there is no vague existence. It might seem that artifacts more generally are the source of tension.

I will now sketch a version of musical creationism, however, on which musical works and other abstracta pose a special problem. I happen to think this view is the most promising of those discussed in this paper, but I will not argue for it here. On the view I have in mind, musical works are made by indicating a sound structure, but, pace Evnine and Fine, they are not made from a sound structure. Works are not made from anything. They are made ex nibilo. Works are also, as Julian Dodd (2007) claims, unstructured - that is, they have no parts. A work has a sound structure. But this is not a parthood, constitution, or identity relation. What it means for the work to have a sound structure is, roughly, that an ideal performance of the work would involve an instance of the structure. That's the view in a nutshell. ${ }^{28}$

Unlike the perduranist and Finean views, on the 'ex nibilo' view, a symphony comes into existence without being ushered in by a plentitude of similar objects. There are no overlapping worms composed of time-slices of a sound structure. Nor is there a plenitude of qua-objects. There's nothing there, so to speak, and then the symphony-and only the symphony'pops' into existence ex nibilo. This absence of plentitude leads to vague existence. When it's indeterminate whether Beethoven has indicated the Ninth Symphony's sound structure, it's indeterminate whether there exists a Beethovenian choral symphony. And, since there is no associated plenitude of objects, nothing is indeterminately such a symphony. We have a counterexample to ' $\nabla \exists \mathrm{xFx} \rightarrow \exists \mathrm{x} \nabla \mathrm{Fx}$ ' and a case of vague existence. ${ }^{29}$

One might prefer neo-Aristotelian theories to the 'ex nibilo' view, if one finds it intuitive that composers create works from abstract parts (e.g., sound types). Conversely, a theorist who finds it hard to imagine abstracta as constituting other abstracta might prefer the 'ex nibilo' view. I won't try to settle this issue here. What's important for present purposes is that the 'ex nibilo' view is reasonable. Moreover, although the view is reasonable when applied to musical works and other abstracta, it does not extend to concrete artifacts. It's far less plausible that people create hammers ex nibilo. People create hammers (and other concrete artifacts) from something else-for example, a handle and a head. People create a house from brick, cement, and/or other materials. One can explain this sort of process-making something from something else-without positing vague existence. ${ }^{30} \mathrm{I}$ conclude that, if the 'ex nibilo' view is correct, musical works (and other abstracta) offer a special reason to accept vague existence-a reason concreta do not offer.

One may object to the 'ex nibilo' view precisely on the grounds that it doesn't extend to concrete artifacts. After all, an advantage of perdurantist

\footnotetext{
${ }^{28}$ This view is similar in some respects to Thomasson's (1999) artifactual theory of fictional characters.

${ }^{29} \mathrm{I}$ am grateful to an anonymous referee for helping me to see that the absence of plenitude is key.

${ }^{30}$ We've seen two ways this can be done: perdurantism and the Finean approach.
} 
and neo-Aristotelian theories is that they offer unified accounts of musical works and concrete artifacts. The 'ex nibilo' view, however, might fare better in other respects. Imagine you're in charge of the Musical Ontology Club. One day you announce: "I hereby declare we have a new position: the treasurer of the Musical Ontology Club; I open the floor for nominations." Plausibly, you create an abstract artifact: the position of treasurer of the club. This happens within a particular social context that includes norms that enable you, as the leader of the club, to create such a position. But it seems wrong to say you create the position from such norms or from your declaration, in the way sculptors create statues from clay. Rather, you create the position in accordance with such norms by making a declaration. Arguably, you create the position ex nibilo. If this is right, the 'ex nibilo' view of music has an advantage of extending to certain abstract artifacts beyond music. The view is worth further consideration.

\section{Conclusion}

There is tension between musical creationism and the view that there is no vague existence. At first glance, Levinson's seminal version of musical creationism implies vague existence. Evnine's related proposal does imply vague existence. The perdurantist and Finean views considered above, however, do not. Some versions of musical creationism, then, are reconcilable with a denial of vague existence. Nonetheless, an alternative view-that musical works are unstructured objects created ex nibilo-offers a special reason for thinking there is vague existence. Two of these views are new: the perdurantist view and the 'ex nibilo' view. I think the latter is especially promising, but I have not argued for it here. I hope to have shown that all of the versions of musical creationism considered here are worth exploring and that some, but not all, imply vague existence. A fruitful way to proceed would be to think more about what exactly a musical work is.

David Friedell

E-mail : dfriedell@barnard.edu

\section{References:}

Baker, Lynne Rudder. 2007. The Metaphysics of Everyday Life: An Essay in Practical Realism. Cambridge: Cambridge University Press.

Caplan, Ben and Carl Matheson. 2006. "Defending Musical Perdurantism." British Journal of Aesthetics 46 (1): 56-59. https://doi.org/10.1093/aesthj/ayj004.

Carmichael, Chad. 2011. "Vague Composition Without Vague Existence." Noûs 45 (2): 315-327.

Acknowledgements For comments and discussion, thanks to Sam Cumming, Simon Evnine, Katrina Elliott, Ashley Feinsinger, Andrew Hsu, Andrew Jewell, David Kaplan, Daniel Korman, Adam Masters, Eliot Michaelson, Terry Parsons, Elliot Paul, Katherine Ritchie, Sheldon Smith, James Van Cleve, audiences at the UCLA Language Workshop and the NYU Language Workshop, and two anonymous referees. 
Cole, Julian. 2004. “An Abstract Status Function Account of Corporations.” Philosophy of the Social Sciences 44 (1): 23-44. https://doi.org/10.1177/0048393112455106.

Currie, Gregory. 1989. An Ontology of Art. New York: St Martin's Press.

Dodd, Julian. 2007. Works of Music: An Essay in Ontology. Oxford University Press.

Evnine, Simon. 2009. "Constitution and Qua Objects in the Ontology of Music." British Journal of Aesthetics 49 (3): 203-217. https://doi.org/10.1093/aesthj/ayp015.

Evnine, Simon. 2016. Making Objects and Events: A Hylomorphic Approach to Artifacts, Actions, and Organisms. Oxford University Press.

Fine, Kit. 1982a. “Acts, Events and Things.” In Language and Ontology: Proceedings of the Sixth International Wittgenstein Symposium, edited by W. Leinfellner E. Kraemer and J. Schank, 97-105. Vienna: Hölder-Pichler-Tempsky.

Fine, Kit. 1982b. "The Problem of Non-Existents-Internalism." Topoi 1: 97-140. https: //doi.org/10.1007/BF00157548.

Fine, Kit. 1999. "Things and Their Parts." Midwest Studies in Philosophy 23 (1): 61-74. https://doi.org/10.1111/1475-4975.00004.

Gibbard, Allan. 1975. “Contingent Idenity." Journal of Philosophical Logic 4 (2): 187-221. https://doi.org/10.1007/BF00693273.

Hawley, Katherine. 2001. "Vagueness and Existence." Proceedings of the Aristotelian Society 102 (1): 125-140. https://doi.org/10.1111/j.0066-7372.2003.00046.x.

Hawthorne, John. 2007. "Craziness and Metasemantics." Philosophical Review 116 (3): 427-440. https://doi.org/10.1215/00318108-2007-004.

Kaplan, David. 1990. "Words." Aristotelian Society Supplementary Volume 64 (1): 93-119. https://doi.org/10.1093/aristoteliansupp/64.1.93.

Kivy, Peter. 1983. "Platonism in Music: A Kind of Defense." Grazer philosophische Studien 19 (1): 109-129. https://doi.org/10.5840/gps19831922.

Korman, Daniel Z. 2014. "The Vagueness Argument Against Abstract Artifacts.” Philosophical Studies 167 (1): 57-71. https://doi.org/10.1007/s11098-013-0232-5.

Korman, Daniel Z. 2015. Objects: Nothing out of the Ordinary. Oxford: Oxford University Press.

Kripke, Saul. 2013. Reference and Existence. John Locke Lectures. Oxford: Oxford University Press.

Levinson, Jerrold. 1980. "What a Musical Work Is.” Journal of Philosophy 77 (1): 5-28. https://doi.org/10.2307/2025596.

Levinson, Jerrold. 2013. "Indication, Abstraction, and Individuation." In Art and Abstract Objects, edited by C. Uidhir, 49-61. Oxford: Oxford University Press.

Lewis, David. 1971. "Counterparts of Persons and Their Bodies." Journal of Philosophy 68 (7): 203-211. https://doi.org/10.2307/2024902.

Lewis, David. 1986. On the Plurality of Worlds. Oxford: Blackwell.

Markosian, Ned. 1998. "Brutal Composition.” Philosophical Studies 92 (3). https://doi.org/ 10.1023/A:1004267523392.

Noonan, Harold W. 2010. "A Flaw in Sider's Vagueness Argument for Unrestricted Mereological Composition." Analysis 70 (4): 669-672. https://doi.org/10.1093/analys/anq070.

Predelli, Stefano. 2001. "Musical Ontology and the Argument from Creation." British Journal of Aesthetics 41 (3): 279-292. https://doi.org/10.1093/bjaesthetics/41.3.279.

Salmon, Nathan. 1998. "Nonexistence." Nô̂s 32 (3): 277-319.

Sider, Theodore. 2001. Four Dimensionalism. Oxford: Oxford University Press.

Thomasson, Amie. 1999. Fiction and Metaphysics. Cambridge: Cambridge University Press.

Trogdon, Kelly and Paisley Livingston. 2014. "The Complete Work." The Journal of Aesthetics and Art Criticism 72 (3): 225-233.

van Inwagen, Peter. 1990. Material Beings. Ithica, NY: Cornell University Press.

von Solodkoff, Tatjana. 2014. "Fictional Realism and Negative Existentials." In Thinking and Talking about Nothing, edited by Manuel García-Carpintero and Genoveva Martí, 333-352. Oxford: Oxford University Press. 